\section{Unusual Case of Subacute Combined Degeneration of Spinal Cord}

Brit. med. F., 1966, 2, 566

Subacute combined degeneration of the cord classically occurs in association with Addison's pernicious anaemia. Over the years improved haematological and biochemical techniques have shown that it can occur in vitamin- $\mathrm{B}_{12}$-deficiency states other than pernicious anaemia: these include cases following gastrectomy, in which most of the intrinsic-factor-producing area may be removed, and in other cases of " malabsorption syndrome." It can also occur in association with fish-tapeworm infestation, particularly in Scandinavia (Woltman and Heck, 1937). A much rarer cause of subacute combined degeneration is when it is due entirely to dietary deficiency of vitamin $B_{12}$.

This is always a possibility in vegans-that is, people who are particularly strict vegetarians and who exclude all animal protein from their diet. The possible reasons why all vegans do not develop subacute combined degeneration was discussed by Smith (1962).

In a review of this subject Richmond and Davidson (1958) gave only two references to this particular cause of subacute combined degeneration (Badenoch, 1954 ; Wokes, 1956), and because of this the following case was thought worth reporting.

\section{CASE REPORT}

A youth first attended the orthopaedic outpatient department at the age of 17 complaining of paraesthesiae of all the fingers of both hands, which his own doctor thought were associated with neck flexion. There was no other relevant history at the time, and on examination no abnormal clinical signs were found. Investigations at that time were normal: $x$-ray examination of cervical spine, N.A.D. ; full blood count, completely normal ; E.S.R., $2 \mathrm{~mm}$. in one hour ; urine, no glycosuria.

It was thought to be a non-specific type of neuritis, and vitamin$B_{1}$ therapy was suggested. It is not known in fact what treatment was eventually given by his general practitioner, but he apparently had no further episode of paraesthesiae.

$\mathrm{He}$ next presented in May 1964, aged 20, complaining of increasing weakness and stiffness of his legs for the previous six months. In addition there had also been occasional hesitancy in passing urine and some soreness of the mouth. There were no other relevant symptoms and his general health was apparently good.

It then came to light that he had all his life existed only on a diet of carbohydrates (mainly bread, chips, and potatoes) and fruit. $\mathrm{He}$ had some milk in his coffee and a little margarine on his bread. He had never eaten green vegetables, animal protein, fish, eggs, cheese, or liver. He did not like them as a young boy, and so had never had them since.

On examination, though he was a little underweight, 9 st. $7 \mathrm{lb}$. $(4.28 \mathrm{~kg}$.) as against an expected weight of $10 \mathrm{st} .10 \mathrm{lb} .(4.82 \mathrm{~kg}$.) for his age and height, he did not look as though he was suffering from malnutrition. His tongue and mouth seemed normal, he was not anaemic, and no spleen was palpable. Cardiovascular, respiratory, and abdominal systems were normal. The nervous system, however, revealed definite abnormal physical signs. The legs were slightly spastic, with bilateral ankle clonus, and both plantar responses were extensor. The tendon reflexes were generally brisk, and particularly so in the legs. There was definite loss of vibration sense below the pelvis and also loss of position sense in the toes. Arm and cranial nerves were normal. A tentative diagnosis of subacute combined degeneration was made, and he was admitted for further investigation.
Investigations.-Haemoglobin $121 \%(17.9$ g./100 ml.); R.B.C. $4,440,000$; colour index 1.25 ; W.B.C. 6,200 , normal differential ; P.C.V. $49 \%$; M.C.V. 103 cubic microns; M.C.H. $38 \mu \mu$ g. ; M.C.H.C. $36 \%$; reticulocytes $<2 \%$. Marrow had a very, active haemopoiesis in which a few of the early normoblasts showed megaloblastic tendencies. Fasting serum iron $195 \mu \mathrm{g} . / 100 \mathrm{ml}$.; total serum protein $8.1 \mathrm{~g} . / 100 \mathrm{ml}$. (albumin $6.5 \mathrm{~g}$. , globulin $1.6 \mathrm{~g}$.) ; serum bilirubin $0.95 \mathrm{mg} . / 100 \mathrm{ml}$. ; blood pyruvic acid $0.42 \mathrm{mg} . / 100 \mathrm{ml}$.; augmented histamine test meal, free $\mathrm{HCl}$; Figlu test, negligible excretion of Figlu in the urine; serum vitamin $B_{12} 71 \mu \mu \mathrm{g} / \mathrm{ml}$. (normal 150-1,000); serum folate $33.8 \mathrm{~m} \mu \mathrm{g}$. (normal 7.5-22.5). The raised folate value may have been due to the blood specimen being taken in the non-fasting state. A Schilling test showed normal absorption of vitamin $\mathrm{B}_{12}$.

\section{Comment}

These results thus showed that he was in fact deficient in vitamin $B_{12}$ and so supported our diagnosis of subacute combined degeneration. The presence of free hydrochloric acid in the stomach rules out classical pernicious anaemia and the Schilling test showed that he was able to absorb vitamin $\mathbf{B}_{12}$. Thus it seemed virtually certain that his deficiency was due to an inadequate intake of vitamin $B_{12}$ as a result of his most unusual diet.

Surprisingly there was no anaemia, but the high fasting serum uron and early marrow changes suggested that this might have been imminent. Megaloblastic anaemia due to dietary deficiency of vitamin $B_{12}$ has been recorded previously in vegans and old people existing on very precarious diets (Harrison et al., 1956; Bourne and Oleesky, 1960). In this case the relatively high intake of folic acid was probably the reason why the subacute combined degeneration developed before the anaemia.

Though this neurological complication as a result of dietary deficiency has been previously reported, and reviewed by Richmond and Davidson (1958), this case seems unique in that the patient was not in the strictest sense either a vegan or a vegetarian. It was simply a food fad carried over from his younger days. Badenoch's (1954) case was similar, though his patient was described as a vegetarian. This patient's diet contained none of the usual sources of vitamin $B_{12}$. Animal protein in the form of meat and fish being the main sources, his diet had lacked both, apparently for most of his life.

As he originally had no intention of changing his dietary habits we thought it safer to treat him with vitamin- $B_{12}$ iniections. On this treatment, though his symptoms have improved, the neurological signs remain virtually the same, except that the plantar responses are probably now flexor. However, his appetite improved so much that he eventually started, and is continuing to take, a normal diet, and his weight has increased from $9 \mathrm{st} .7 \mathrm{lb}$. to $10 \mathrm{st} .8 \mathrm{lb}$. (4.28 to $4.76 \mathrm{~kg}$.). As we know he is able to absorb vitamin $B_{12}$, we have now discontinued his injections.

My thanks to Dr. R. T. Gaunt, consultant physician, Royal Hospital, Chesterfield, for encouragement and permission to publish this case, and to Mrs. Stevenson for secretarial help.

C. J. RILEY, M.B., CH.B., D.OBST.R.C.O.G., M.R.C.P.GLASG., Medical Registrar, Royal Hospital, Chesterfield.

\section{REFERENCES}

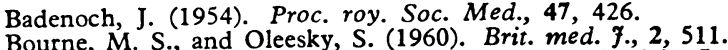

Bourne, M. S., and Oleesky, S. (1960). Brit. med. (1956). Lancet, 1, 727.

Harrison, R. J., Booth, C. C., and Mollin, D. L. (1956). Lancet, 1,

Richmond, J., and Davidson, S. (1958). Quart.

Smith, A. D. M. (1962). Brit. med. F., 1, 1655.

Wokes, F. (1956). Proc. Nutr. Soc., 157, Arch. intern. Med., 60, 272. 